\title{
A INVESTIGAÇÃO-AÇÃO COLABORATIVA COMO SUPORTE METODOLÓGICO À MEDIAÇÃO INTERCULTURAL
}

\author{
Cristina Pereira ${ }^{1}$, Fátima Santos ${ }^{2}$ e Sónia Faria ${ }^{3}$ \\ 11nstituto Politécnico de Castelo Branco, Portugal. cristina.pereira@ipcb.pt \\ ${ }^{2}$ Cáritas Interparoquial de Castelo Branco, Portugal. gascaritas@sapo.pt \\ ${ }^{3}$ Agrupamento de Escolas Afonso de Paiva, Portugal. soniafarias@gmail.com
}

\begin{abstract}
Resumo A presente proposta de comunicação organiza-se como uma análise das potencialidades da metodologia de investigação-ação colaborativa na operacionalização de processos de mediação intercultural, tendo por base a descrição reflexiva do processo de integração de uma família de refugiados numa cidade do interior de Portugal. A opção por este desenho metodológico cumpriu o duplo objetivo de nos permitir conhecer e caracterizar a realidade em análise e intervir no sentido de implementar o processo de integração social e, muito particularmente, o processo de inclusão escolar das 7 crianças da família em análise. 0 delineamento da pesquisa revelou-se adequado às circunstâncias e aos objetivos do estudo, permitindo organizar dados, definir estratégias e implementar dinâmicas promotoras do processo de integração e, paralelamente, o desenvolvimento pessoal e/ou profissional dos intervenientes. A avaliação positiva da metodologia e dos procedimentos adotados no presente estudo tem permitido a replicação dos procedimentos como suporte à integração de outras famílias de refugiados.
\end{abstract}

Palavras-chave: Investigação-Ação Colaborativa; Mediação Intercultural; Rede Articulada de Intervenção; Inclusão Escolar.

\section{COLLABORATIVE ACTION RESEARCH AS A METHODOLOGICAL SUPPORT FOR INTERCULTURAL MEDIATION}

\begin{abstract}
This communication proposal is organized as an analysis of the potential of the collaborative action-research methodology in the operationalization of intercultural mediation processes, based on the reflective description of the process of integration of a refugee family in a city in the interior of Portugal. The option for this methodological design allowed us to fulfill the double objective of allowing us to know and characterize the reality under analysis and to intervene in order to implement the process of social integration and, particularly, the process of school inclusion of the 7 children in the family under analysis. The research design proved to be adequate to the circumstances and objectives of the study, allowing to organize data, define strategies and implement dynamics that promote the integration process and, in parallel, the personal and / or professional development of the stakeholders. The positive evaluation of the methodology has allowed for the replication of procedures to support the integration of other refugee families.
\end{abstract}

Keywords: Collaborative Research-Action; Intercultural Mediation; Articulated Intervention Network; School Inclusion.

\section{INTRODUÇÃO}

A União Europeia confronta-se atualmente com um afluxo de refugiados numa escala sem precedentes desde a $2^{2}$ Guerra Mundial.

A International Organization for Migration (2017) refere que, desde janeiro de 2015, chegaram à Europa mais de um milhão de pessoas, sendo a maioria originária de países em 
situação de conflito, como a Síria ou o Iraque. Por sua vez, os dados disponíveis no Portal da Plataforma de Apoio aos Refugiados (PAR) (2019) indicam que cerca de $55 \%$ dos refugiados vêm da Síria, do Afeganistão e do Sudão do Sul. Só na Síria, em 2017, 2/3 da população deslocou-se para fugir à guerra civil, à perseguição e ao terror.

Os refugiados fazem parte daquilo que se designa comummente por "migrantes forçados", emigrando por razões alheias à sua vontade. Oriundos de lugares de guerra e devastação, veem-se impedidos de regressar, por um período que se prevê longo, ao lugar de onde foram obrigados a partir, sob o risco de perderem a sua própria vida (Santinho, 2013).

A integração dos refugiados nos países europeus de acolhimento tem colocado desafios e dificuldades relacionados com a dimensão/escala, mas também com as variáveis culturais, linguísticas e sociais que o fenómeno mobiliza. O processo de integração depende de uma multiplicidade de fatores relacionados com a confluência entre as condições e representações culturais dos países de acolhimento com os traumas, as expetativas e os desejos que os refugiados perseguem (Pasikowska-Schnass, 2017).

A publicação da United Nations Refugee Agency (UNHCR), de 2002, "Refugee Resettlement - An International Handbook To Guide Reception and Integration", descreve a integração dos refugiados como um processo multifacetado e mutuamente dinâmico que implica a criação de condições para a sua participação nos aspetos da vida económica, social, cultural, civil e política dos países de acolhimento.

A mesma publicação realça o importante papel do reconhecimento da cultura dos refugiados no processo de integração, perspetivando essa dimensão como uma contribuição significativa para as atuais sociedades multiculturais. No entanto, a diversidade cultural presente atualmente nos países europeus tem tido impactos e mensagens contraditórios e ambíguos. A história tem demonstrado que em momentos de crise económica se verifica um renascimento de atitudes intolerantes e xenófobas perante as culturas minoritárias. Por outro lado, há também registo de experiências de inclusão positiva, em que a multiculturalidade se organiza como uma oportunidade para a promoção da coesão social e a capacitação das populações (McGregor \& Ragab, 2016).

Tendo como pano de fundo a problemática da integração de refugiados na sociedade portuguesa, o artigo propõe-se evidenciar o contributo da metodologia de investigação-ação colaborativa na operacionalização de processos de mediação intercultural. A articulação 
entre os pressupostos e as metodologias da investigação-ação e da mediação intercultural permitiram-nos gerar respostas mais integradas e dinâmicas ao longo do processo de acolhimento e integração de uma família de refugiados sírios numa cidade do interior de Portugal. A opção metodológica tornou possível cumprir o duplo objetivo de nos permitir conhecer e caracterizar a realidade em análise e intervir de uma forma integrada e sistémica.

Os resultados que apresentamos, e que se traduzem em alguns indicadores de sucesso no processo de integração da família em análise, de uma forma mais evidente na inclusão escolar e no processo de aprendizagem das crianças da família, só puderam ser alcançados através de uma postura de envolvimento, partilha de responsabilidades, comunicação fluida, análise ponderada e contínua das decisões entre os participantes no estudo. Envolver a família no processo, ouvindo e considerando a sua "voz", contribuiu para uma aprendizagem em ação e para a capacitação de todos os intervenientes, reforçando uma rede de articulação fundamental para dar resposta ao objetivo subjacente ao presente estudo.

\section{INTERVIR NA COMUNIDADE: O PAPEL DO MEDIADOR INTERCULTURAL NA INTEGRAÇÃO DE REFUGIADOS}

Os fenómenos da globalização, diversidade e complexidade que caracterizam as sociedades contemporâneas têm mobilizado novas formas de convivência e de organização social no pressuposto da construção de sociedades em que o relacionamento e a comunicação entre pessoas de culturas diversas e identidades múltiplas seja uma oportunidade para o desenvolvimento pessoal, cultural e social. Os países atuais integram múltiplas formas de viver que são expressões de outras tantas culturas que reclamam a sua afirmação em espaços múltiplos e diversos.

Nos atuais contextos multiculturais, a figura do mediador emerge como interveniente central na operacionalização de respostas adequadas e processos de comunicação integrada entre os intervenientes em relação/confronto.

A mediação intercultural procura, por um lado, valorizar e afirmar as diferenças culturais, étnicas e sociais dos grupos minoritários, de modo a consolidar a sua identidade e, por outro, dar a conhecer publicamente essas diferenças, de modo a que exista um reconhecimento da pluralidade constitutiva da própria sociedade, facilitando a inter-relação e intercompreensão entre os grupos. No contexto atual, a mediação intercultural tem vindo a 
impor-se como um recurso organizado, com o qual se pretende fortalecer a coesão e os laços sociais (https://adcmoura.pt/pareescuteolhe/?p=273).

O mediador intercultural assume um papel complexo, mas central, nos processos de integração dos refugiados e, de acordo com Giménez (2010), deve ter uma conceção dinâmica da identificação do papel dos preconceitos e estereótipos na relação interpessoal e social que se medeia, das particularidades da comunicação intercultural e do conflito interétnico e das inter-relações entre a pessoa, a sua situação e enquadramento cultural.

O processo de integração de refugiados nas sociedades de acolhimento assume dimensões complexas e multifacetadas, exigindo ajustamentos mútuos e progressivos que, ao longo de um período temporal mais ou menos longo, permitem, ou não, a construção de um espaço de comunicação e de culturas partilhadas entre as comunidades recém-chegadas e os autóctones.

O papel do mediador deve, pois, assentar numa conceção e atuação sistémicas que potenciem a integração individual e comunitária. As exigências e responsabilidades envolvidas neste processo dizem respeito a vários atores: os próprios refugiados, o governo de acolhimento, definidor das políticas associadas ao processo, as instituições sociais e educativas e a comunidade como um todo.

Na perspetiva de Liddicoat (2016, p.355)

a more productive way to think about intercultural mediation is to see it as a relational and interpretative activity. (...) This means that intercultural mediation is not solely the resolution of communication problems but also the development of shared understandings between participants in communication.

De acordo com o exposto, a mediação intercultural assume diferentes facetas, mas o foco da nossa atuação foi a promoção da integração da família de refugiados associada a uma participação social e cívica.

Os mediadores envolvidos potenciaram os processos de comunicação/mediação de significados, de educação e de regulação social entre as partes, gerando a possibilidade de negociação e mediação criadora de um espaço comum. A atuação inseriu-se na mediação comunitária que, na perspetiva de Almeida, Albuquerque e Santos (2012), tem como 
objetivos prevenir ou resolver conflitos, criar e reforçar a comunicação entre as redes de apoio, bem como promover o empoderamento individual e comunitário.

Foi sobretudo nossa preocupação assumir a definição de mediação explicitada por Maria José Casa-Nova $(2009$, p. 62, 63) quando refere que

Mediar significa autonomizar os atores, criando condições para a construção de poder. Neste caso, autonomização e construção de poder significam possibilitar àqueles que são "mediados" uma aprendizagem potenciadora de uma autorresolução, uma prevenção de conflitos e uma aprendizagem em ação que se transforma em capacidade de atuação.

\section{PLANO DE INTERVENÇÃO E METODOLOGIA}

\subsection{Questão de investigação}

Considerando os desafios e as dificuldades que o processo de integração dos refugiados nos países europeus de acolhimento tem colocado, poderá o planeamento de uma investigação-ação colaborativa a par dos procedimentos subjacentes à mediação intercultural, organizarem-se como uma resposta de intervenção adequada?

\subsection{Objetivos}

O delineamento da intervenção mobilizou a ação de diferentes serviços da comunidade, envolvendo a família num processo de auscultação, levantamento de necessidades e interesses. Tendo por base o problema, os parceiros envolvidos definiram os seguintes objetivos:

- Conceber e implementar um projeto de mediação intercultural assente na metodologia de investigação-ação participativa.

- Articular os princípios e metodologias da investigação-ação e da mediação intercultural.

- Operacionalizar processos de coordenação partilhada para a definição de estratégias e ações tendo em vista a integração da família na comunidade e a definição de um projeto escolar para as 7 crianças da família.

- Definir e (re)organizar uma atuação concertada entre os diferentes parceiros de forma a garantir a inclusão escolar e a aprendizagem das crianças.

- Monitorizar de forma contínua o processo de integração, envolvendo a família nesse processo. 


\subsection{Desenho metodológico}

A investigação-ação é um método de investigação de natureza predominantemente qualitativa que se organiza em ciclos sucessivos de planificação, ação e avaliação reflexiva de uma realidade social concreta. Pressupõe a inter-relação do investigador com a realidade que estuda e onde intervém, fazendo com que a construção da teoria se processe de modo indutivo e sistemático, a partir do próprio contexto e à medida que os dados empíricos emergem (Máximo-Esteves, 2008).

Podemos considerar que para Lewin (1946) a investigação-ação é encarada como uma aplicação da metodologia científica à clarificação e à resolução de problemas sociais concretos. É, também, um processo que envolve mudanças pessoais e sociais deliberadas e planificadas. Em ambos os sentidos, constitui um processo de aprendizagem que dá particular relevo à qualidade de colaboração no planeamento da ação e na avaliação dos resultados.

A investigação-ação é, pois, uma metodologia que quando utilizada pelos profissionais em exercício Ihes permite ensaiarem ações progressivamente mais adequadas, distinguindo-se da prática profissional habitual por terem como suporte processos de análise e avaliação rigorosos e partilhados.

Uma investigação-ação colaborativa tem como objetivo central a ação, envolvendo investigadores que são atores no(s) contexto(s) em análise. De acordo com Bryant (1995, p. 8)

collaborative action research can therefore be defined as a variety of stakeholders cooperating together to explore questions of mutual interest through cycles of action, experience and reflection, in order to develop insights into particular phenomena, create frameworks for understanding, and suggest actions which improve practice.

De acordo com os objetivos e o contexto de realização do estudo optou-se por operacionalizar uma investigação-ação inscrita na categoria definida por Bryant (1995). Esta metodologia permitiu cumprir o duplo objetivo de nos permitir conhecer e caracterizar a realidade em análise e intervir no sentido de implementar o processo de integração de uma família de refugiados, durante um período temporal de 1 ano e 4 meses. Tivemos como guia alguns dos procedimentos identificados no eixo de atuação "Famílias" da responsabilidade 
da Plataforma de Apoio aos Refugiados (PAR), bem como o suporte concetual e operativo da mediação intercultural explicitado anteriormente.

Esta opção metodológica permitiu implementar com maior eficácia as mudanças pretendidas pois operacionaliza-se em processos integrados de ação e investigação tendo subjacente uma análise sistémica. Baseada numa sucessão de processos de planificação, intervenção/ação, observação, registo e reflexão da realidade em análise, envolveu os protagonistas nos procedimentos da pesquisa.

\subsection{Participantes no estudo}

Foram participantes intervenientes na investigação-ação a Cáritas Interparoquial da cidade, através da sua diretora e psicóloga estagiária, o Agrupamento de Escolas, através do seu diretor e professoras envolvidas mais diretamente na lecionação das crianças; uma Associação de Desenvolvimento Local, através da sua diretora e técnicas do Centro Local de Apoio à Integração de Migrantes (CLAIM); a Unidade Local de Saúde, através da psicóloga da Consulta de Desenvolvimento; uma Instituição do Ensino Superior, através de um dos membros da equipa da RESMI e a família de refugiados, doravante designada por JS.

A Família JS é originária da Síria e integrava 9 membros (os pais e sete filhos menores, com idades entre os 5 e os 15 anos, à data de chegada a Portugal, ou seja, em setembro de 2017).

\subsection{Procedimentos}

- Realização de reuniões regulares com o objetivo de avaliar o processo de integração, reorganizar estratégias e analisar alternativas de intervenção;

- Observação e avaliação contínua das crianças, aferindo a sua evolução e dificuldades;

- Operacionalização de medidas que pretendiam dar resposta a anseios manifestados pelos pais ou pelas crianças.

- Respeitar os procedimentos éticos relativos a um estudo desta natureza. A identificação dos organismos envolvidos foi devidamente autorizada pelos participantes no estudo e que integram os diretores ou responsáveis institucionais. Respeitámos o anonimato da família e 
os pais $\mathrm{S}$ e $\mathrm{F}$ assinaram um consentimento informado no momento da realização das entrevistas formais, na presença da tradutora.

\subsection{Técnicas e instrumentos de recolha de dados}

- Entrevistas formais e informais aos pais e crianças; observação participante; notas de campo; evidências de aprendizagem na escola (desenhos, textos...); registos de Incidentes Críticos; escalas e testes psicológicos padronizados (WISC - subescala de realização, considerando as dificuldades de domínio da língua portuguesa; Prova "Era uma Vez", de Teresa Fagulha, 1997).

\section{O PERCURSO DO PROCESSO DE INTEGRAÇÃO - ALGUNS RESULTADOS}

\subsection{A chegada da família à comunidade}

A Família JS foi acolhida numa cidade do interior de Portugal no âmbito do programa "Cáritas Acolhe", que prevê um apoio que se prolonga por um período de 24 meses. Nesse sentido, quando a família chegou foi-Ihe cedida uma casa de habitação social, pertencente à Câmara Municipal.

A casa foi equipada com os bens materiais essenciais, incluindo eletrodomésticos, sendo explicado à família que mensalmente teriam o apoio alimentar por parte da instituição. Desde então, iniciou-se um trabalho conjunto de integração, em articulação com diversos organismos.

Assim, no que respeita ao apoio social, a família foi, desde a chegada, acompanhada por técnicas de serviço social da Cáritas e do gabinete CLAIM de uma Associação de Desenvolvimento local, bem como por uma psicóloga da Cáritas. Procedeu-se à inscrição no Centro de Saúde local, à obtenção de número do Sistema Nacional de Saúde, à inscrição na Segurança Social, além de terem sido operacionalizados os procedimentos necessários para a obtenção dos apoios sociais de direito. Foi ainda efetuado o acompanhamento aos diversos serviços, para a obtenção de documentos, às consultas médicas, vacinações e à realização de exames médicos.

No que respeita à integração escolar das crianças, foram planeadas e postas em práticas medidas com o objetivo de que o percurso fosse o mais próximo de uma educação inclusiva. Assim, numa primeira fase, os menores foram integrados numa mesma escola pertencente 
a um Agrupamento de Escolas da cidade. Tratava-se de uma escola com Jardim de Infância e Primeiro Ciclo que, numa fase de integração inicial, se mostrou como a resposta mais adequada. Assim, no dia 20 de setembro de 2017, as três crianças mais novas da família iniciaram a frequência do Jardim de Infância. Os restantes menores iniciaram as aulas quando a professora de língua portuguesa não materna iniciou o seu trabalho na escola, dia 3 de outubro do mesmo ano. A partir daí, estas crianças passaram a ter aulas tanto ao nível de aprendizagem da língua e cultura portuguesa, como posteriormente de matemática, estudo do meio e expressão artística, para que mais tarde, pudessem ser incluídas em turmas de acordo com o nível etário e competências adquiridas.

Foi dada a conhecer à família a possibilidade de frequentarem aulas de português para estrangeiros, ministradas por uma professora voluntária, na Associação de Desenvolvimento Local. Trata-se de aulas de língua portuguesa de nível básico e com uma carga horária semanal de 2 horas. A mãe, FA, iniciou ainda uma Ação de Formação em Língua Portuguesa para Estrangeiros, no âmbito do Programa PPT- Português para Todos. O pai, S, inscreveu-se no Centro de Emprego em outubro de 2017 e celebrou um contrato de emprego de inserção com a Câmara Municipal, tendo o mesmo a duração de nove meses. Assim, a 13 de outubro de 2017, iniciou a sua atividade laboral na área de manutenção e reparação de espaços públicos, jardins e espaços verdes.

\subsection{Perfil desenvolvimental e aspetos socioemocionais das crianças}

No que respeita ao perfil desenvolvimental das crianças da família, e de acordo com as observações, notas de campo e avaliações realizadas nos primeiros meses de integração no contexto escolar, verificou-se a existência de grandes disparidades entre a fratria. Enquanto as crianças mais novas não evidenciaram problemas significativos de regulação socioemocional ou de desenvolvimento cognitivo, constatou-se que os dois filhos mais velhos do casal evidenciavam algumas dificuldades nestes domínios. Em concreto, desde as primeiras semanas em Portugal que foi claro que $A$, o filho mais velho da fratria, apresentava alguns comportamentos de inconformidade perante a mudança e para com a estadia em Portugal. Eram comuns os episódios de raiva e indignação, episódios de comportamento agressivo e descontrolado, tanto em contexto familiar, como na convivência com técnicos ou na escola. 
As suas reações eram imprevisíveis, salientando-se que, em situações de contrariedade das suas vontades ou desejos, a sua tolerância à frustração era extremamente baixa. Era assim evidente a falta de mecanismos de coping adequados e ferramentas de resolução de problemas. De acordo com as notas de campo organizadas pela professora "Desde o início, todos têm demonstrado real interesse em aprender a Língua Portuguesa, sendo A quem mais resiste e quem se recusa a executar algumas das tarefas propostas. É notória e evidente a sua contrariedade em estar na escola, em desempenhar tarefas escolares, em obedecer a regras, em cumprir deveres e em respeitar quem o rodeia” (...) Na escola, foi demonstrando insatisfação, desagrado e tédio. Quando questionado acerca do seu estado emocional, sentindo-se incomodado, proferia um discurso agressivo, acompanhado de muitos gestos. Referiu, por diversas vezes, que pretende voltar para a Turquia para posteriormente voltar para a Síria, o seu lugar.Face a este comportamento, os seus irmãos mantêm-se em silêncio, de olhar triste e rosto fechado. (...) É um jovem adolescente emocionalmente muito instável e com bastante dificuldade em regular as suas emoções. Consegue passar de um estado de euforia para um estado de agressão em poucos minutos, ofendendo verbalmente quem o rodeia, fazendo frente com um olhar ameaçador. Urge um acompanhamento psicológico que o ajude a regular as suas emoções e a desenvolver alguns mecanismos de defesa relativamente às memórias, às vivências e às cicatrizes que trouxe da infância".

Face a estes problemas, iniciou-se um processo de acompanhamento por uma pedopsiquiatra do Hospital Pediátrico de Coimbra - Centro Hospitalar de Coimbra, EPE, e de apoio psicológico pelas psicólogas da Cáritas e da Consulta de Desenvolvimento da ULS, ainda que com alguma resistência inicial por parte de $A$.

\subsection{O desenrolar do processo de inclusão escolar e comunitária}

De acordo com o memorando da 5a Reunião dos parceiros envolvidos no apoio à integração da Família JS, realizada a 18 de outubro de 2018, ou seja, passados 13 meses após a sua chegada à cidade de acolhimento, o ponto da situação relativamente ao processo de integração e transição escolar das crianças era o seguinte:

- O filho mais velho, designado por A, estava a iniciar um Curso de Educação e Formação (CEF) num outro Agrupamento de escolas da cidade, prosseguindo uma via mais profissionalizante. Esta decisão teve em consideração a opinião dos diferentes intervenientes no processo, nomeadamente a opinião dos pais e de A que, a partir do $2^{\circ}$ 
período do ano letivo anterior, demonstrou o desejo de sair da Escola do Castelo, onde estava com os irmãos, pelo facto de ser um estabelecimento frequentado apenas por crianças do pré-escolar e 1ํ ciclo do Ensino Básico.

A mudança no percurso escolar de A apoiou-se, portanto, na caracterização etária e comportamental do adolescente, bem como no percurso realizado no passado ano letivo, já que no $3^{\circ}$ período do ano letivo anterior $A$ conciliou a frequência da escola frequentada pelos seus irmãos, durante as manhãs, de forma a reforçar as suas competências na Língua Portuguesa, com a ida diária à sede do Agrupamento onde frequentou aulas de música e atividades em clubes extracurriculares, com alunos do 2ª ciclo do Ensino Básico.

Em geral, a integração no novo contexto estava a ser positiva apesar do seu comportamento continuar a revelar alguma instabilidade e dificuldades em controlar a expressão de emoções negativas. Continuava a ser seguido em consulta de pedopsiquiatria, em Coimbra, mas reduziu a necessidade de fazer uso de medicação e a regularidade das consultas.

- J, $2^{\circ}$ irmão da fratria, e AM, a criança de género feminino mais velha, aguardavam a transição para a sede do Agrupamento, no final do mês de outubro, onde estava prevista a frequência de algumas disciplinas da área das expressões, numa turma do 5o ano. Paralelamente, estava programado o apoio fora da sala de aula nas áreas da matemática e das ciências naturais, bem como a frequência de alguns clubes, tendo em vista o desenvolvimento de competências transversais fundamentais para o seu processo de socialização e o reforço das competências na Língua Portuguesa.

A decisão sobre a transição destas duas crianças para uma nova escola teve na sua base não só o seu nível etário mas também algumas preocupações relativamente ao seu percurso desenvolvimental.

Os diferentes intervenientes consideraram que esta mudança, mesmo que não isenta de algumas preocupações e alguma necessidade de apoio, lhes iria permitir desenvolver algum sentido de afirmação pessoal e de autonomia, pelo facto de poderem contactar com crianças mais próximas do seu nível etário, constituindo modelos de identificação importantes. 
O facto de A ter transitado para uma escola diferente e, considerando o seu poder sobre os seus irmãos mais novos, permitiu a $A M$ e $J$ uma maior afirmação das suas identidades e conquista de autonomia.

- As crianças mais novas continuavam a frequentar a mesma escola, integradas em turmas adequadas ao seu nível de aprendizagem. Destacamos o caso de $\mathrm{N}$, a criança mais velha a permanecer nesse contexto, frequentando uma turma do $2^{\circ}$ ano de escolaridade. Esta criança continuava a revelar competências e motivação no processo de aprendizagem, sendo o caso de maior sucesso de inclusão no contexto escolar. Revelava um domínio adequado da língua portuguesa e também competências de ajustamento socioemocional.

Foi ainda referida a possibilidade de $\mathrm{N}$ começar a frequentar uma academia ou clube de ginástica, considerando o seu interesse e competências evidenciadas nesta área.

De acordo com o exposto, após um ano da sua vinda para esta cidade, as crianças que no primeiro ano letivo estiveram juntas numa turma com o apoio de uma professora que pretendeu garantir a aprendizagem da língua portuguesa, transitaram para outras turmas de acordo com o seu nível etário e competências adquiridas, dando início a um percurso escolar mais próximo de uma educação inclusiva.

No ano letivo de 2018-2019 foi colocada uma outra professora para garantir o apoio na aprendizagem da Língua Portuguesa mas a sua intervenção decorreu no contexto espacial e temporal do funcionamento das turmas que as crianças frequentavam.

Se no momento de acolhimento, perante um ambiente estranho, pleno de desafios socioculturais, emocionais, cognitivos e linguísticos, foi importante que os elementos da fratria se mantivessem juntos no mesmo espaço escolar e com a mesma professora, garantindo a continuidade de cumplicidades e da dinâmica relacional estabelecida entre eles, foi também importante ponderar a progressiva transição para diferentes contextos de acordo com o seu nível desenvolvimental, assegurando, ao mesmo tempo, o contacto com outras aprendizagens e novas interações sociais.

A professora desempenhou um papel primordial como figura securizante, assegurando a transição para a comunicação, a convivência e a exploração do "novo mundo". 


\section{ANÁLISE FINAL - CONSTRANGIMENTOS E EVIDÊNCIAS DE SUCESSO}

A integração de refugiados nos países de acolhimento é um processo complexo e em construção contínua, dependente das teias relacionais e comunicativas que se vão estabelecendo. Segundo Machado (2002) citado por Zarro (2017, p. 18) “a integração a longo prazo pode ser sinónimo da consolidação entre a população autóctone e as populações migrantes de um sentimento recíproco de pertença à mesma sociedade global". A integração está, pois, intrinsecamente relacionada com o envolvimento e participação nas dinâmicas económica, cultural, educacional e cívica de uma sociedade.

Uma das dimensões que, na nossa perspetiva, se organiza como uma evidência desse processo é a construção de projetos de futuro (a médio e longo prazo) projetados nos contextos do país de acolhimento. Dependendo das experiências vivenciadas durante o período de acolhimento, os refugiados percecionam de forma diferenciada a integração, desenvolvendo, ou não, uma perceção positiva e de confiança que condicionará as suas ações e os seus projetos.

A análise da situação atual da família permite-nos identificar um percurso de integração individual e social com algumas evidências de sucesso. A família conta atualmente com mais uma criança já nascida em Portugal e, de acordo com os dados recolhidos na entrevista realizada em dezembro de 2018, gostariam de continuar na cidade que os acolheu depois de terminado o período de acolhimento (setembro de 2019), situação que continua a verificar-se até à presente data.

A análise da situação escolar das diferentes crianças revela que estão a realizar progressos nas aprendizagens formais evidenciando alguma integração social no contexto educativo. Fizeram progressos notáveis na aprendizagem da língua portuguesa, base estruturante da aquisição de diferentes áreas do conhecimento.

Por outro lado, iniciaram um percurso escolar mais adequado às especificidades do seu nível etário e características individuais, o que tem permitido o desenvolvimento de relações interpessoais mais diversificadas, quer com o grupo de pares quer com diversas figuras adultas de referência. Persistem, naturalmente, inseguranças e conflitos associados a aspetos culturais (Exs.: alimentação, vestuário, período do Ramadão) que têm sido assumidos de uma forma cuidadosa e atenta pelos responsáveis educativos e pela família. 
Evidenciamos, como dimensão facilitadora dos resultados alcançados, a atitude que os pais têm manifestado, valorizando a importância da aprendizagem e o papel da escola nesse processo.

Centrando-nos na análise do sistema familiar, constatámos que, se os primeiros meses na cidade de acolhimento evidenciaram uma estrutura fechada ao mundo exterior, hierárquica e rígida na distribuição de funções e poder, tem-se verificado uma progressiva abertura aos sistemas envolventes.

Para além de fatores culturais que condicionam os modelos de organização dos sistemas familiares, podemos associar o funcionamento familiar inicial à necessidade da família se manter unida perante as adversidades que vivenciaram, sentindo ser necessário manter uma atitude de alguma desconfiança perante as "ameaças" exteriores. Entretanto, foram progressivamente construindo uma relação de confiança com os diferentes interlocutores envolvidos no apoio à sua integração, assistindo-se a uma progressiva autonomia dos diferentes membros da fratria, geradora de novas dinâmicas familiares.

Um dos exemplos de "abertura" evidenciada pela família traduz-se nos convites para alguns dos participantes no estudo visitarem e almoçarem na casa da família ou na sua participação em eventos organizados pela Associação de Desenvolvimento Local e as relações sociais e de entreajuda que mantém com alguns elementos da vizinhança.

Existe, contudo, um constrangimento relacionado com o facto do pai, $\mathrm{S}$, estar neste momento desempregado.

A situação laboral do pai assume, na nossa perspetiva, um papel central no processo de integração de toda a família pelo que a diretora da Cáritas, em coordenação com a Associação de Desenvolvimento Local, está preocupada em analisar as alternativas de trabalho disponíveis. Será um processo que necessita ser negociado com o casal, valorizando o seu papel para o equilíbrio e bem-estar da família. Permanecer na comunidade que os acolheu após o período formal de acolhimento tem permitido reforçar as aprendizagens já alcançadas, a construção de um sentimento de estabilidade e continuidade relacional, garantia de confiança e de investimento num projeto de vida. 


\section{CONSIDERAÇÕES FINAIS}

A investigação-ação colaborativa constitui, na nossa perspetiva, uma via insubstituível para a produção de conhecimento orientado para a ação, permitindo delimitar um problema específico, planificar e intervir de forma particular e sistémica. Ao longo da realização do estudo, nenhum dos intervenientes assumiu de forma individual o papel de mediador intercultural, mas as relações delineadas e construídas permitiram que as dinâmicas específicas dos processos de mediação fossem (re)construídas na interação. As práticas de mediação intercultural estão intrinsecamente relacionadas com a operacionalização de conceitos como a comunicação, o diálogo, a participação, a capacitação, a inclusão e coesão sociais. De acordo com Silva, Piedade, Morgado e Ribeiro (2016, p.12) "a mediação é um procedimento que privilegia a cooperação e a participação dos mediados na procura de uma solução para os seus conflitos ou problemas, mutuamente satisfatória e potencialmente duradoura. Ao promover a participação na construção de soluções satisfatórias, promove simultaneamente a aprendizagem da cooperação, a construção dos laços sociais e a coesão social."

Tendo como base a análise destes pressupostos é possível e pertinente identificar pontos convergentes entre os desenhos investigativos assentes na investigação-ação colaborativa e as metodologias de suporte à intervenção em mediação intercultural. Mais do que pontos de convergência, salientamos o papel de enriquecimento conceptual e metodológico que a articulação entre estas duas abordagens pode potenciar, permitindo operacionalizar um modelo alternativo de intervenção promotor de transformações mútuas e integradas, de educação e autonomização dos atores e das comunidades intervencionadas.

De acordo com o exposto, o delineamento da pesquisa revelou-se adequado às circunstâncias e aos objetivos do estudo, permitindo organizar dados, (re)definir estratégias e implementar dinâmicas promotoras do processo de integração e, paralelamente, o desenvolvimento pessoal e/ou profissional dos intervenientes.

Pretendemos, contudo, afirmar a necessidade de prosseguir a investigação-ação iniciada pois é fundamental continuar a monitorizar o processo e definir estratégias que sustentem o desenvolvimento do processo de integração dos diferentes membros da família JS. Há também a decisão de estender o estudo a outras famílias de refugiados Sírios, acolhidos mais recentemente pela Cáritas Interparoquial, bem como de partilhar a experiência desenvolvida com profissionais e organismos noutros locais do território nacional. 


\section{REFERÊNCIAS}

Almeida, H., Albuquerque, C. \& Santos, C. (2012), Dinâmicas processuais e estratégicas da mediação em contextos de conflito e de mudança social, comunicação apresentada no VIIIth International Conference of the World Mediation Forum "Tiempo de mediación, Liderazgo y Accion para el Cambio", realizado entre 18 e 21 de Outubro de 2012, Valência (Disponível em https://www.researchgate.net/publication/323784524_Dinamicas_processuais_e_estrategicas_da_mediaca o_em_contextos_de_conflito_e_de_mudanca_social).

Associação para o Desenvolvimento do Concelho de Mora (2015). A Mediação Intercultural. Portal Pare, Escute e Olhe. (disponível em https://adcmoura.pt/pareescuteolhe/?p=273).

Bryant, P. (1995). Collaborative Action Research - On the cutting edge. Disponível em https://www.uleth.ca/dspace/bitstream/.../Bryant_Paul.pdf?...1...

Casa-Nova, M. (2009). A Mediação Intercultural e a Construção de Diálogos entre Diferentes: Notas soltas para reflexão. Comentário ao Painel: Mediação Intercultural, Actas do Seminário Mediação Socioeducativa: $\begin{array}{llll}\text { Contextos Actores. } & \text { e } & \text { (Disponível } & \text { em }\end{array}$ https://www.dge.mec.pt/sites/default/files/EPIPSE/contributos_de_maria_jose_casa_nova.pdf

Fagulha, T. (1997). Era uma Vez, Prova Projectiva para Crianças. Lisboa: CEGOC

Fagulha, T. (1997). Manual e Caderno de Registo de Respostas da Prova Projectiva, "Era uma Vez", para Crianças. Lisboa: CEGOC

Giménez, R. (2010). Interculturalidade e Mediação. Lisboa: Alto Comissariado para a Imigração e Diálogo Intercultural, I. P.

International Organization for Migration (2017). International Migration Report. United Nations. Disponível em http://www.un.org/en/development/desa/population/migration/publications/migrationreport/docs/MigrationRe port2017_Highlights.pdf).

Lewin, K. (1946). Action research and minority problems. Journal of Social Issues, 2(4), 34-46.

Liddicoat, A. (2016). Intercultural mediation, intercultural communication and translation. Perspectives Studies in Translation Theory and Practice 24(3), 354-364. Taylor \& Frances Online, disponível em https://doi.org/10.1080/0907676X.2014.980279.

Máximo-Esteves, L. (2008). Visão panorâmica da Investigação-Acção. Porto: Porto Editora.

McGregor, E., \& Ragab, N. (2016). The Role of Culture and the Arts in the Integration of Refugees and Migrants. Disponível em https://www.merit.unu.edu/publications/uploads/1473335881.pdf.

Santinho, M. (2013). Afinal, que Asilo é este que não nos protege?. Lisboa: ISCTE - Instituto Universitário de Lisboa.

Silva, A., Piedade, A., Morgado, M. \& Ribeiro, M. (2016). Entre Iguais e Diferentes: a Mediação Intercultural. Atas das I Jornadas da Rede de Ensino Superior para a Mediação Intercultural. Alto Comissariado para as Migrações, I.P. http://repositorio.esepf.pt/bitstream/20.500.11796/2374/1/Atas_RESMI_final.pdf.

Zarro, S. (2017). Perspetivas de Integração por parte dos Refugiados numa Comunidade do Litoral de Portugal. (Dissertação de Mestrado), Instituto Politécnico de Leiria, Leiria. Disponível em https://iconline.ipleiria.pt/bitstream/10400.8/3020/1/DissertacaoMestradoSusanaZarro.pdf. 